\title{
Libertad religiosa y Estado Constitucional
}

\author{
Samuel B. Abad Yupanqui*
}

La libertad religiosa es un derecho fundamental que se encuentra estrechamente vinculado con el proceso de consolidación de un Estado Constitucional de Derecho. Así se puede apreciar de los debates suscitados desde la reforma y la contrarreforma hasta las revoluciones americana y francesa. Por eso, el destacado constitucionalista español Javier Pérez Royo afirma que «la lucha por su reconocimiento ha sido el motor que acabaría desembocando en el Estado constitucional» ${ }^{1}$.

En este sentido, el presente artículo pretende examinar la evolución del debate constitucional sobre las relaciones Estado-Iglesia en nuestro país, el actual diseño de estas relaciones a partir de lo dispuesto por el texto constitucional vigente y el Acuerdo suscrito con la Iglesia Católica en julio de 1980, así como los alcances de un proyecto de ley que pretende regular la libertad e igualdad religiosas. Asumiendo tal perspectiva recordaremos algunos antecedentes constitucionales que nos muestran por donde se ha encaminado el debate; y examinaremos los principios que orientan la relación Iglesia-Estado, desde un enfoque de derechos fundamentales y en el marco de la indispensable afirmación de un Estado Constitucional de Derecho. Ello es particularmente relevante en un país como el nuestro en donde determinadas concepciones religiosas pretenden establecerse como único parámetro para la adopción de aquellas políticas públicas respecto a las cuales la Iglesia tiene una posición definida.

Profesor de Derecho Constitucional de la Pontificia Universidad Católica del Perú. Socio del Estudio Echecopar Abogados

1 Perez Royo, Javier. Curso de Derecho Constitucional. Séptima edición. Madrid: Marcial Pons, 2000, p. 353. 


\section{La relación Iglesia y Estado en las constituciones peruanas}

\section{EL ALEJAMIENTO DEL MODELO FRANCÉS Y NORTEAMERICANO}

La Declaración Francesa de los Derechos del Hombre y del Ciudadano del primero de octubre de 1789 adoptó una clara posición sobre la libertad religiosa. En efecto, en su artículo 10 precisó que «Nadie debe ser molestado por sus opiniones, aunque sean religiosas, con tal que su manifestación no turbe el orden público establecido por la ley».

Es decir, se reconoció la libertad religiosa y se prohibió todo tipo de molestias frente a ella. En dicho momento, pese a que la Asamblea estaba conformada por una cuarta parte de eclesiásticos, prosperó un ambiente de tolerancia. «El celo de los protestantes en hacer notar la discriminación civil de que eran objeto hacía difícil, si no imposible, la proclamación de un culto católico dominante» ${ }^{2}$. Así, en la sesión del 23 de agosto de 1789, cuando se discutió la libertad religiosa, Honoré-Gabriel Riquett, conde de Mirabeau pronunció un importante discurso a favor de la tolerancia dirigido a quienes querían hacer predominar la religión católica en la vida civil.

¿Hablaban como católicos o como legisladores? [...] cuidar de que ningún culto, ni siquiera el vuestro, perturbe el orden público, tal es vuestro deber, pero no podéis ir más lejos. Una opinión que sería la del mayor número no tiene el derecho de dominar ${ }^{3}$

Por su parte, en los Estados Unidos de América, la Constitución de 1787 fue objeto de una primera enmienda en 1791 que reconoció la libertad religiosa. Dicha enmienda señaló que «El Congreso no dictará leyes acerca del establecimiento de una religión o de la prohibición de su libre ejercicio». Esta disposición no solo reconoció un derecho, sino a la vez estableció la separación entre la Iglesia y el Estado.

El grado de esta separación — como anota Corwin — ha sido objeto de un intenso debate por parte de la Corte Suprema de los Estados Unidos. Por un lado, algunos han interpretado que «lo que la cláusula prohíbe es el trato preferencial dispensado a una religión o una secta por el gobierno

2 Faure, Christine. Las declaraciones de los derechos del hombre de 1789. México: Comisión Nacional de Derechos Humanos, Fondo de Cultura Económica, 1995, p. 22.

3 Citado por Faure, Christine. Ob. cit., p. 367. 
de Estados Unidos", mientras que otros consideran que la norma tiene por propósito «levantar un muro divisorio entre la Iglesia y el Estado»

Estas dos experiencias de países occidentales - Francia y Estados Unidos- que contribuyeron decididamente al desarrollo del constitucionalismo en América Latina, ¿̨ueron tomadas en cuenta para la regulación de las relaciones Iglesia y Estado en el Perú? En nuestro país, como veremos, la influencia española ha marcado la relación Iglesia y Estado en la mayoría de nuestras Constituciones.

\section{LA INFLUENCIA ESPAŃOLA EN LOS TEXTOS CONSTITUCIONALES}

En España, a diferencia de los Estados Unidos y de Francia, la situación fue radicalmente distinta. Los Reyes católicos trataron de cimentar la unidad nacional sobre la base de la unidad religiosa ${ }^{5}$. Ello contribuyó a promover la intolerancia, recordemos, por ejemplo, la triste experiencia del Tribunal de la Santa Inquisición. Así, la Constitución de Cádiz de 1812 muestra una evidente diferencia con los textos franceses y norteamericano. En efecto, su artículo 12 señalaba que:

La religión de la Nación española es y será perpetuamente la católica, apostólica, romana, única verdadera. La Nación la protege por leyes sabias y justas, y prohíbe el ejercicio de cualquier otra.

¿Qué incidencia tuvo la citada disposición de la Constitución de Cádiz en el desarrollo del constitucionalismo peruano y en la relación Iglesia y Estado? Para contar con mayores elementos de juicio, citaremos la primera Constitución peruana (1823), pues nos brinda una idea de la fuente de inspiración. En efecto, su artículo 8 señalaba que: «La religión de la República es la católica, apostólica, romana, con exclusión del ejercicio de cualquiera otra».

Corwin, Edward S. La Constitución de los Estados Unidos y su significado actual. Buenos Aires: Editorial Fraterna, 1987, p. 373.

5 Así lo señala BARRERO, Abraham. «Sobre la libertad religiosa en la historia constitucional española». Revista Española de Derecho Constitucional, N ${ }^{\circ}$ 61, Madrid: Centro de Estudios Políticos y Constitucionales, 2001, p. 138. 
Dicha norma fue repetida por todas las Constituciones peruanas del siglo XIX y principios del siglo $\mathrm{XX}^{6}$. Sin embargo, desde inicios de la República también se reconocieron ciertas atribuciones al Estado respecto a la Iglesia Católica. Se trató del denominado «Patronato Nacional» que era:

Una herencia del Patronato Regio, concedido por la Santa Sede a los Reyes de Espańa, desde el tiempo de la Conquista de América, y que consistía en el derecho que la Santa Sede concedía a los Monarcas o Jefes de Estado, de proponer sujetos que considerasen idóneos para los diversos cargos, dignidades y beneficios eclesiásticos, a cambio de la protección que ejercerían a favor de la actividad de la Iglesia Católica.

Como en otros países de América, al emanciparse de la Corona española, el Perú reivindicó el Patronato para su Gobierno ${ }^{7}$

En esa dirección, la Constitución de 1933 señaló que «El Estado ejerce el patronato nacional conforme a las leyes y a las prácticas vigentes» (artículo 233). Agregaba que era atribución del Congreso elegir arzobispos y obispos a propuesta de una terna del Poder Ejecutivo. Posteriormente esta

6 Luego de la Constitución de 1823 podemos citar los siguientes textos fundamentales: 1826: «La religión del Perú es la católica, apostólica, romana» (artículo 6).

1828: «Su religión es la católica, apostólica, romana. La nación la protege por todos los medios conformes al espíritu del Evangelio, y no permitirá el ejercicio de otra alguna» (artículo 3).

1834: «Su religión es la católica, apostólica, romana. La nación la protege por todos los medios conformes al espíritu del Evangelio, y no permite el ejercicio de otra alguna» (artículo 2).

1839: «Su religión es la católica, apostólica, romana, que profesa sin permitir el ejercicio público de cualquier otro culto» (artículo 3).

1856: «La Nación profesa la religión católica, apostólica, romana. El Estado la protege por todos los medios conforme al espíritu del Evangelio, y no permite el ejercicio público de otra alguna» (artículo 4).

1860: «La Nación profesa la religión católica, apostólica, romana. El Estado la protege y no permite el ejercicio público de otra alguna» (artículo 4).

1867: «La Nación profesa la religión católica, apostólica, romana. El Estado la protege, y no permite el ejercicio público de otra alguna» (artículo 3).

1920: «La Nación profesa la religión católica, apostólica, romana. El Estado la protege» (artículo 5),

1933: «Respetando los sentimientos de la mayoría nacional, el Estado protege la religión, católica, apostólica y romana. Las demás religiones gozan de libertad para el ejercicio de sus respectivos cultos» (artículo 232).

7 Carpio Sardón, Luis Andrés. La libertad religiosa en el Perú. Derecho Eclesiástico del Estado. Piura: Universidad de Piura, 1999, p. 310. 
disposición fue modificada, confiriéndole tal función al Congreso, pero conservando el Presidente de la República ciertas atribuciones para presentar al Congreso las ternas para la elección de arzobispos y obispos pues se establecía que el Presidente podía hacer presentaciones para dignidades. Cabe precisar que el Patronato Nacional dejó de existir con el Concordato y la Constitución de 1979.

Esto significa que la relación Estado-Iglesia a lo largo del constitucionalismo peruano del siglo XIX y parte del XX se ha caracterizado por reconocer a la religión católica como la religión oficial, excluyendo a todas las demás. Ello, de la mano con algunas atribuciones al Estado respecto a la Iglesia que se han venido ejerciendo con mayor o menor intensidad y formalizado de manera explícita en las Constituciones a través de la institución del «Patronato Nacional».

\section{El cambio propuesto por la Constitución de 1979 y el Con- CORdato o ACUerdo suscrito con la Iglesia Católica durante el GOBIERNO MILITAR}

El gobierno militar, como paso previo a la entrega del poder a los civiles, convocó a una Asamblea Constituyente (1978-1979) que debía elaborar una nueva Constitución, la misma que entró en vigencia en julio de 1980. Ella introdujo un cambio sustantivo respecto a los textos anteriores. En efecto, la Constitución de 1979 señaló, respecto a las relaciones EstadoIglesia que:

Artículo 86.- Dentro de un régimen de independencia y autonomía, el Estado reconoce a la Iglesia católica como elemento importante en la formación histórica, cultural y moral del Perú. Le presta su colaboración.

El Estado puede también establecer formas de colaboración con otras confesiones.

De esta manera, la citada norma marcó una distancia entre el Estado y la Iglesia, eliminó el patronato, y estableció una mención especial a la Iglesia Católica. Por su parte, el artículo 2 inciso 3) reconoció la libertad religiosa y el Preámbulo mantuvo un expreso reconocimiento a Dios («Nosotros, representantes a la Asamblea Constituyente, invocando la protección de Dios»). 
¿Y cómo se llegó a diseñar este tipo de relación entre Estado e Iglesia? Si se examina el debate constitucional, puede apreciarse que en la sesión realizada el 2 de noviembre de 1978 se invitó a la Comisión de Constitución a representantes de la Iglesia Católica para formular sus propuestas. Asistió en representación de la Iglesia, monseñor José Dammert Bellido, entonces Vicepresidente de la Conferencia Episcopal de Acción Social, quien en términos generales propuso el contenido del artículo que se encuentra en las Constituciones de 1979 y de 1993.

Nosotros creemos, conforme al Concilio Vaticano II [...], en una independencia y autonomía entre el Estado y la Iglesia, con la necesaria colaboración, porque no se trata de dos entidades que viven en países distintos, sino que están dentro del mismo país. [...]

De ahí el proyecto que hemos presentado. Los títulos son muy sencillos. Existiendo la necesidad de la libertad religiosa [...]; luego la del reconocimiento de la independencia, de la autonomía y de la colaboración con las confesiones religiosa, y dado el hecho sociológico de que en el Perú más del noventa por ciento, según los últimos censos, se declaran que son católicos, tiene que haber una especial coordinación con la Iglesia Católica para el servicio de la comunidad ${ }^{8}$.

La propuesta presentada por monseñor Dammert reconocía la libertad religiosa, la independencia y autonomía de la Iglesia respecto al Estado, y proponía reconocer una colaboración especial con la Iglesia Católica para el servicio de la comunidad ${ }^{9}$. De esta manera, el texto actualmente vigente, que es el mismo al de la Constitución de 1979, surgió de una propuesta presentada por la Iglesia Católica inspirada en el Concilio Vaticano II. Cabe indicar que la doctrina del Vaticano II plantea una separación entre Iglesia y Estado que no es absoluta, conforme lo explicó el reverendo Francisco Interdonato:

8 Comisión Principal de Constitución de la Asamblea Constituyente 1978-1979. Diario de los Debates, Tomo I, Lima, p. 138.

9 El tema económico no fue ajeno al debate. Monseñor Dammert pensaba que «Todos los templos, casas parroquiales, conventos y obispados, yo creo que deben estar exonerados, porque son para el servicio de la comunidad, y es diferente de los bienes que producen rentas». Comisión Principal de Constitución de la Asamblea Constiturente 19781979. Ob. cit., p. 141. 
[...] Esa separación no puede ser absoluta, completa; primero porque el mismo ciudadano lo es tanto del Estado como de la Iglesia, y segundo porque el propio Estado, en cuanto realidad humana creada, está ordenado a Dios y debe integrarse en el orden establecido ${ }^{10}$.

Pero, si se examina esto con mayor detenimiento, puede apreciarse que detrás de estas concesiones también había el interés de eliminar el patronato a favor del Estado, que subsistía en el texto constitucional de 1933; y por otro, el interés en mantener una especial mención constitucional a la Iglesia Católica.

Sin embargo, no basta con examinar el texto constitucional para determinar el grado de neutralidad del Estado peruano. Cabe recordar que la Constitución de 1979, que entró en vigencia en julio de 1980, se elaboró como paso previo a la salida de un gobierno militar y la entrega del poder a un gobierno civil. En el camino, el Gobierno militar suscribió un Acuerdo Bilateral de carácter internacional con la Iglesia Católica que mantuvo diversos privilegios.

El Acuerdo celebrado entre la Santa Sede y la República del Perú el 19 de julio de 1980 concluye un largo proceso que comenzó junto con la vida republicana, al incorporarse en la tercera Constitución (1828) la posibilidad de llegar a la firma de un Concordato con la Iglesia en relación al Patronato y a otras materias de común interés ${ }^{11}$.

El Concordato con la Iglesia Católica, suscrito el 19 de julio de 1980, reconoce los cambios introducidos por la Constitución de 1979 pero a la vez mantiene y consagra algunos privilegios que brevemente seńalamos:

a) El sistema de subvenciones para las personas y servicios de la Iglesia, los cuales seguirían como hasta el momento de su suscripción; además, se precisó que las asignaciones personales no tienen carácter de sueldo, ni de honorarios y, por tanto, no constituyen renta sujeta a tributo (artículo 8);

b) La Iglesia Católica continuará gozando de las exoneraciones y beneficios tributarios con los que ya contaba (artículo 10); esto ha

\footnotetext{
10 Interdonato, Francisco S.J. «Relaciones de la Iglesia y el Estado en la nueva Constitución del Perú». Revista Derecho, N 35, Lima: PUC, junio 1981, p. 88.

11 Carpio Sardón, Luis Andrés. Ob. cit., pp. 336-337.
} 
sido interpretado por el Ministerio de Relaciones Exteriores como un «régimen de exoneración permanente»;

c) El Estado continuará garantizando que el vicariato castrense preste la asistencia religiosa a los miembros de las Fuerzas Armadas, Policiales y autoridades civiles, a través de los capellanes religiosos (artículo 11);

d) El nombramiento de los profesores de religión católica de los centros públicos, en los que se continuará impartiendo como materia ordinaria $^{12}$, requerirá la aprobación del obispo respectivo. Es decir, el profesor de religión se mantendrá en su cargo mientras goce de la aprobación del obispo (artículo 19).

Al respecto se ha señalado que "para la Iglesia Católica este instrumento significó el logro de una meta que persiguió desde que el Perú nació como República» ${ }^{13}$, cuyos privilegios no son compartidos por las restantes confesiones religiosas y que han generado algunos cuestionamientos.

Así por ejemplo, en Colombia la Corte Constitucional a través de la sentencia $\mathrm{N}^{\circ} \mathrm{C}-027 / 93$ del 5 de febrero de 1993, declaró inconstitucionales algunos artículos del Concordato y Protocolo Final entre la República de Colombia y la Santa Sede, suscrito en Bogotá el 12 de julio de 1973 y aprobado por la Ley 20 de 1974. Uno de los temas discutidos fue el de la educación religiosa. La Corte sostuvo que:

Si se coteja el artículo XII (del Acuerdo) con la normación superior antes comentada, surge la contrariedad de aquel con esta última, pues, el estudiante de plantel oficial, sea católico o no, recibirá las enseñanzas de la Iglesia Católica, pues los planes educativos forzosamente deberán incluir tal enseñanza. Fuera de ello se discrimina en relación con las otras confesiones religiosas. [...]

Lo que se censura frente al nuevo Estado Constitucional, es que compulsivamente sea esa la única enseñanza que deba impartirse en los

12 Así por ejemplo, la Resolución Ministerial № 0019-2004-ED de 23 de enero de 2004 que autoriza la implementación del «Diseño Curricular Básico de Educación Secundaria de Menores» al referirse al contenido del área de educación religiosa se refiere básicamente a la religión católica.

13 Carpio Sardón, Luis Andrés. Ob. cit., p. 300. 
centros educativos del Estado, sin que se de opción al alumnado de recibir la de su propia fe, o de no recibir ninguna ${ }^{14}$.

En el Perú este debate no ha sido planteado. Sin embargo, sí se han presentado casos en los cuales Iglesias y colegios religiosos no católicos han exigido un tratamiento tributario igual al que gozan sus similares católicos (Exp. N 1123-99-AA/TC).

\section{El modelo adoptado por la Constitución de 1993}

\section{El artículo 50 de la Constitución y el debate constitucional}

Durante el proceso de elaboración de la Carta de 1993 por parte del Congreso Constituyente Democrático (CCD) no hubo mayor debate respecto al mantenimiento de la fórmula prevista por la Constitución de 1979. Es más, el artículo 50 de la Constitución de 1993 fue aprobado por unanimidad por la Comisión de Constitución y Reglamento ${ }^{15}$. El texto vigente señala que:

Artículo 50.- Dentro de un régimen de independencia y autonomía, el Estado reconoce a la Iglesia Católica como elemento importante en la formación histórica, cultural y moral del Perú y le presta su colaboración.

El Estado respeta otras confesiones y puede establecer formas de colaboración con ellas.

Además el diminuto preámbulo de esta Constitución continuó haciendo una mención teísta al señalar que «El Congreso Constituyente Democrático, invocando a Dios Todopoderoso, [...]».

Sin embargo, sí se apreció una intensa discusión en torno a la maternidad y paternidad responsables y el derecho de las personas a decidir, estar informadas y acceder a los «medios» naturales y artificiales respectivos, donde las convicciones católicas se introdujeron al debate constitucional.

14 Citado por Cepeda Espinoza, Manuel José. Derecho Constitucional Jurisprudencial. Las grandes decisiones de la Corte Constitucional. Bogotá: Legis, 2001, p. 201.

15 Comisión de Constitución y Reglamento del Congreso Constituyente Democrático. Diario de los Debates, Tomo IV. Lima, p. 2188. 
Esto ocurrió en la $66^{\circ}$ Sesión (Vespertina) de la Comisión de Constitución y Reglamento realizada el 2 de junio de $1993^{16}$.

El señor FERRERO COSTA (NM-C90).- Hay una palabra que crea problemas. Es la palabra 'medios', salvo que la Comisión precisara, y constara así, a qué se está refiriendo, porque normalmente 'medios' se refiere a medios artificiales y medio naturales, ¿no es verdad?

El señor FREUNDT-THURNE OYANGUREN (NM-C90).- Así es, exactamente. Nosotros creemos que la pareja debe decidir en plena libertad.

El señor FERRERO COSTA (NM-C90).- El problema sería, Presidente, que se estaría reconociendo, aun cuando fuese de manera tácita, la protección constitucional a la recurrencia de los medios artificiales, $y$, entonces, la Constitución iría a un campo al que no fue hace tres años y estaría declarando — por supuesto, yo sé que esto es opinión de muchas personas- que los medios artificiales no son inevitables, sino mejores.

Pero para otras personas, que también son bastantes, y para quienes - aunque no necesariamente siempre puedan cumplirlo — creen en la doctrina de la Iglesia Católica, los únicos medios son los naturales, y los demás son medios inválidos moralmente.

Entonces, hay un problema con esa palabra, y la Comisión no debería pasar el tema así nomás.

Ante este cuestionamiento a la propuesta formulada, surgieron voces críticas respecto a la eventual confesionalidad de la Constitución que se venía elaborando.

El señor FREUNDT-THURNE OYANGUREN (NM-C90).- [...] Yo no creo —y pido mil disculpas - que esta sea una Constitución católica; creo que esta es una Constitución peruana. Con el respeto que le tengo a la Iglesia Católica —y se lo tengo en gran cantidad-, yo he peleado y he defendido la cuestión del aborto hasta la saciedad.

$[\ldots]$

El señor CHIRINOS SOTO (R).- No es una versión católica, doctor Freundt-Thurne, porque no es una versión confesional; es una versión

16 Comisión de Constitución y Reglamento del Congreso Constituyente Democrático. Diario de los Debates, Tomo V, Lima, pp. 2684-2685. 
hecha por católicos para un país católico en el que no hace falta comprarse un pleito con la Iglesia. Nada más.

Como puede apreciarse el factor religioso se introdujo en el debate constitucional, aunque finalmente primó el espíritu de tolerancia pues el artículo 6 de la Constitución estableció que «el Estado asegura los programas de educación y la información adecuados y el acceso a los medios, que no afecten la vida o la salud».

\section{LA PROPUESTA CONTENIDA EN EL PROYECTO DE REFORMA CONSTITU- CIONAL}

Luego de la caída del régimen de Fujimori se planteó el debate sobre la necesidad de efectuar una reforma constitucional. Ante esta situación, se aprobó la Ley 27600 que dispuso la «reforma total» de la Constitución de 1993 a través del Congreso. La Comisión de Constitución, Reglamento y Acusaciones Constitucionales presidida por el entonces congresista Henry Pease, se encargó de la conducción del proceso que finalmente fue suspendido en abril de 2003. No obstante, varios dispositivos fueron aprobados por el Pleno en una primera votación.

Precisamente, el proyecto de reforma constitucional aprobado por el Pleno por setenta votos a favor (once en contra y doce abstenciones) mantuvo el primer párrafo de lo dispuesto por la Constitución de 1979, pero efectuó algunos cambios al segundo ${ }^{17}$. El artículo 71 disponía que:

Dentro de un régimen de independencia y autonomía, el Estado reconoce a la Iglesia Católica como elemento importante en la formación histórica, cultural y moral del Perú y le presta su colaboración.

El Estado reconoce y respeta a todas las confesiones religiosas y establece acuerdos de colaboración con ellas, a través de sus órganos representativos, con criterio de equidad.

El párrafo final del citado dispositivo agregó la palabra «reconoce», lo cual generó algunas críticas ${ }^{18}$. En efecto, la Constitución vigente dice

\footnotetext{
Congreso de la República. «Memoria de la Comisión de Constitución, Reglamento y Acusaciones Constitucionales. Períodos 2001-2002; 2002-2003». Lima, 2003, p. 77.

18 Díaz MuÑoz, Oscar. «Libertad de conciencia y de religión en la reforma constitucional». Ponencia presentada al Congreso de Derecho Constitucional realizado en la ciudad de Piura en agosto de 2002.
} 
«respeta» otras confesiones; en cambio, la propuesta decía «reconoce y respeta». Decir «reconoce» implica, desde una perspectiva jurídica, que cualquier otra confesión es reconocida por la Constitución; con ello se afirma que automáticamente existirían todas las demás confesiones distintas a la Iglesia Católica. Por tanto, cualquier religión, de haberse aprobado el texto tal cual, estaría automáticamente reconocida sin necesidad de constituirse como persona jurídica.

De otro lado suele argumentarse que la mención a la Iglesia Católica en la Constitución se debe a que es un «elemento importante en la formación histórica, cultural y moral del Perú». Sin embargo, dicho agregado no resulta necesario y bien podría ser excluido en aras de evidenciar una clara intención de establecer una separación entre las Iglesias y el Estado, tal como lo formularon algunas propuestas de minoría. Así por ejemplo resulta sugerente la propuesta formulada por el Concilio Nacional Evangélico del Perú según la cual:

El Estado, cumpliendo con su papel de velar por el bien común y reconociendo el principio universal de igualdad de oportunidades ante la ley para todos los ciudadanos, se define como un Estado no confesional; no obstante reconoce, respeta y garantiza la libertad e igualdad religiosa.

El Estado, dentro de un régimen de independencia y autonomía, debe establecer formas de colaboración con las distintas confesiones religiosas ${ }^{19}$.

No obstante, nuevamente se apreció la incidencia del factor religioso en el debate constitucional. Esto, por ejemplo, se presentó cuando se discutió el tema referido al aborto, pues algunos - como el entonces congresista Rafael Rey, perteneciente al Opus Dei- plantearon incluir una norma que lo prohibiera sin establecer excepción alguna. Pese a ello, la norma aprobada (artículo 2) estableció que «Está prohibido el aborto, salvo la excepción permitida por ley».

A nuestro juicio, no se debería mencionar al aborto en la Constitución pues se trata de un tema que debe ser desarrollado por la ley. Esta inclusión generó una pública crítica del Cardenal de Lima en su homilía del 24 de

19 Congreso de la República. «Aportes ciudadanos al debate del Anteproyecto de Ley de Reforma de la Constitución», Volumen IV, Lima, 2003, pp. 311-312. 
noviembre de 2002, quien pretendiendo anteponer sus convicciones religiosas para prohibir el aborto —incluyendo al terapéutico-, calificó de una "tremenda hipocresía y cobardía» la propuesta de reforma constitucional formulada ${ }^{20}$. Como acertadamente señaló Mario Vargas Llosa ${ }^{21}$, la Iglesia Católica «[...] no tiene derecho alguno de prohibir a quienes no son católicos actuar de acuerdo a sus propios criterios y a su propia conciencia, en una sociedad donde, afortunadamente, el Estado es laico».

Este rápido repaso nos permite apreciar que, a diferencia de otros países, el Perú se ha inspirado en la experiencia española. Eso ha significado que durante siglos ha existido una estrecha vinculación entre Estado-Iglesia Católica. La Constitución de 1979 fue un hito cuyos postulados se mantienen en la Carta de 1993. Sin embargo, cuando se toma en cuenta este tema, no hay que dejar de lado lo que significa el Concordato, que incluye algunos reconocimientos especiales a favor de la Iglesia Católica.

\section{LOS PRINCIPIOS ORIENTADORES DE LA RELACIÓN IGLESIA-ESTADO}

La doctrina suele identificar los principios que informan al denominado Derecho eclesiástico e identifican a un Estado Constitucional indicando que «son la libertad religiosa, la igualdad religiosa, la laicidad o aconfesionalidad del Estado, y la cooperación con las confesiones religiosas» ${ }^{22}$. Así también lo reconoce la Constitución de 1993, tal como veremos a continuación.

\subsection{La libertad e igualdad religiosas}

Existen determinados principios que determinan las relaciones existentes entre el Estado y las confesiones religiosas. Uno de ellos, es el reconocimiento de la libertad religiosa. Ello permite que cualquier persona pueda creer o no creer en un dios o considerar que no existe.

20 En tal ocasión sostuvo «Es una tremenda hipocresía, una tremenda cobardía que pretende incluirse en la Constitución de nuestro país» < http://www.arzobispadodelima. org/palabras/2002/ho241102.htm > .

21 VARGas Llosa, Mario. "Cobardía e hipocresía». Revista Caretas, № 1751, diciembre, 2002, p. 35.

22 Gutiérrez del Moral, María Jesús y Miguel Angel Cañivano Salvador. El Estado frente a la religión: jurisprudencia constitucional española y del Tribunal Europeo de Derechos Humanos. Barcelona: Atelier, 2003, p. 31 
Consiste en el derecho a mantener las ideas y convicciones propias sobre el origen del hombre, sobre la existencia de un ser (o varios) superior al hombre y creador del universo, o sobre concepciones análogas sobre el origen y sentido del universo ${ }^{23}$.

Este derecho cuenta, además, con dos facetas, una interior y otra exterior; es en esta última donde suelen presentarse restricciones. De tal manera, cualquier prohibición o sanción por profesar una determinada religión resulta hoy inaceptable.

La Carta de 1993 reconoce la libertad religiosa en su artículo 2 inciso 3) al señalar que toda persona tiene derecho a la libertad «de religión, en forma individual o asociada. No hay persecución por razón de ideas o creencias. El ejercicio público de todas las confesiones es libre, siempre que no ofenda la moral ni altere el orden público». Asimismo, el artículo 2 inciso 2) reconoce la igualdad religiosa y, en consecuencia, prohíbe toda discriminación por motivo de religión. Finalmente, el artículo 2 inciso 18) reconoce el derecho de mantener reserva sobre las convicciones religiosas.

El Tribunal Constitucional en el caso Lucio Valentín Rosado Adanaque contra el Seguro Social de Salud (Essalud) (Expediente Nº 0895-2001AA/TC-Lambayeque, resuelto el 19 de agosto de 2002) consideró que la libertad religiosa faculta a toda persona a «[...] formar parte de una determinada confesión religiosa, de creer en el dogma y la doctrina propuesta por dicha confesión, de manifestar pública y privadamente las consecuentes convicciones religiosas y de practicar el culto». En una sentencia posterior, de 15 de julio de 2004, entendió que comprendía cuatro atributos:

a) reconocimiento de la facultad de profesión de la creencia religiosa que libremente elija una persona, b) reconocimiento de la facultad de abstención de profesión de toda creencia y culto religioso, c) reconocimiento de la facultad de poder cambiar de creencia religiosa, d) reconocimiento de la facultad de declarar públicamente la vinculación con una creencia religiosa o de abstenerse de manifestar la pertenencia a alguna. Es decir, supone el atributo de informar, o no informar, sobre tal creencia a terceros (Expediente $\mathrm{N}^{\circ}$ 3283-2003-AA/TC, Caso: Taj Mahal Discoteque y otros, FJ. 18).

23 Espin, Eduardo y otros. Derecho Constitucional. Tercera edición. Valencia: Tirant lo blanch, 1997, Vol. I, p. 208. 


\subsection{El principio de neutralidad, laicidad o no confesionalidad}

El principio de laicidad del Estado, que identifica a un Estado laico, se conoce también como el principio de no confesionalidad o de neutralidad. $Y$ es que en un Estado Constitucional no puede haber confesiones que tengan carácter estatal. Así por ejemplo, el Tribunal Constitucional español en su sentencia STC 24/1982 ha señalado respecto a dicho principio que «El artículo 16.3 de la Constitución proclama que ninguna confesión religiosa tendrá carácter estatal e impide por ende [...] que los valores o intereses religiosos se erijan en parámetros para medir la legitimidad o justicia de las normas y actos de los poderes públicos» ${ }^{24}$.

El fundamento de la laicidad del Estado se encuentra en la dignidad del ser humano. En efecto, como señala María Roca:

[...] atendiendo a su sentido actual, puede decirse, que la causa de la neutralidad y la tolerancia está en la igual dignidad de todo hombre, que no permite al Estado adoptar decisiones que solo al ciudadano corresponden ${ }^{25}$.

Sin embargo, todavía vemos en la realidad algunas reminiscencias que desconocen este principio, porque la neutralidad implica que la religión no puede convertirse expresa o implícitamente en un parámetro para medir la legitimidad o justicia de las normas o de una política del Estado. De esta manera, para decidir si los seres humanos tienen que conocer los medios de reproducción asistida o determinados medios para vivir su sexualidad, esa política no debe ser evaluada desde una perspectiva religiosa, porque si fuera así, sencillamente estaríamos desconociendo el principio de neutralidad. Así por ejemplo, tampoco el Gobierno podría declarar el año de la Virgen María, porque estaría haciéndolo en función de un fenómeno religioso. Esta discusión ha llegado a algunos medios de comunicación, tal como puede apreciarse en un editorial («Laicismo y confusión») del diario oficial El Peruano publicado el 18 de diciembre de 2002, donde se afirmó de manera exagerada que:

24 Citado por Perez Royo, Javier. Ob. cit., p. 358.

25 Roca, María J. «La neutralidad del Estado: fundamento doctrinal y actual delimitación en la jurisprudencia». Revista Española de Derecho Constitucional, $\mathrm{N}^{\circ}$ 48. Madrid: Centro de Estudios Constitucionales, 1996, p. 260. 
El sueño racionalista de crear sociedades más libres a partir de la descristianización produjo los monstruos del relativismo moral, y la eliminación del concepto de responsabilidad y de culpa individual genera los totalitarismos neopagano y ateo, del hitlerismo y del estalinismo, respectivamente.

Por eso es que cuando se dice que un país tiene un sistema basado en el pluralismo y que respeta la libertad religiosa, quiere decir que todas las instituciones públicas, e incluso los centros docentes públicos, deben ser ideológicamente neutrales, tanto expresa como implícitamente. En algunos países, como Colombia, este principio también ha sido desarrollado jurisprudencialmente. Así por ejemplo, la Corte Constitucional en la sentencia C-1175-04 (considerando 13) de 24 de noviembre de 2004 sintetizó los principios que orientan las relaciones entre Iglesia y Estado:

(i) separación entre Estado e Iglesias de acuerdo con el establecimiento de la laicidad del primero (C-088/94 y C-350/94), (ii) prohibición de injerencia alguna obligatoria, que privilegie a la religión católica o a otras religiones en materia de educación (C-027/93), (iii) renuncia al sentido religioso del orden social y definición de este como orden público en el marco de un Estado Social de Derecho (C-088/94 y C-224/94), (iv) determinación de los asuntos religiosos frente al Estado, como asuntos de derechos constitucionales fundamentales (C088/94), (v) prohibición jurídica de injerencia mutua entre Estado e Iglesias (C-350/94), (vi) eliminación normativa de la implantación de la religión católica como elemento esencial del orden social (C350/94) y (vii) establecimiento de un test que evalúa si las regulaciones en materia religiosa están acordes con los principios de pluralidad y laicidad del Estado colombiano (C-152/2003).

En tal ocasión, la Corte declaró inconstitucional el Decreto 1355 de 1970 que establecía la conformación del Comité de Clasificación de Películas señalando que uno de sus cinco miembros debía ser un representante de la Iglesia Católica, pues consideró que «El carácter laico del Estado colombiano hace que la Corte encuentre contrario a la Constitución la participación obligatoria (derecho de representación) de una religión en una instancia de decisión estatal»(Considerando 27). En el Perú el desarrollo jurisprudencial no ha sido tan intenso e incluso en alguna ocasión ha sido desafortunado, tal como sucedió cuando el Tribunal Constitucional declaró infundada una demanda de amparo que cuestionaba la Ordenanza 
Municipal No 039-MPH-CM, de 29 de marzo de 2001, dictada por la Municipalidad Provincial de Huancayo que prohibía la venta y consumo de licor en los bares, videopubs, discotecas, clubes nocturnos y similares desde la 00:00 horas del viernes santo hasta las 06:00 horas del sábado santo. El Tribunal consideró que dicha prohibición era plenamente válida, desconociendo que un gobierno local no puede imponer la abstención de consumo de esta clase de bebidas con motivo de una fecha religiosa (Exp. №3283-2003- AA/TC, Caso: Taj Mahal Discoteque y otros ${ }^{26}$ ).

\subsection{Cooperación o colaboración en el marco de la laicidad del Estado}

Paralelamente surge otro principio, el de colaboración con las confesiones. La Constitución reconoce la autonomía pero también la cooperación con las confesiones. No obstante efectúa un reconocimiento especial a la Iglesia Católica. En realidad se trata del reconocimiento a una situación sociológica — sin duda, podría evitarse—, y que no resulta extraño que se incluya en algunos textos constitucionales tal como ha sucedido en España.

La mención expresa y deliberada de la Iglesia Católica entre los sujetos beneficiarios de la colaboración no puede interpretarse como una excepción de la regla de la confesionalidad del Estado, sino como una concesión a una realidad histórica y sociológica ${ }^{27}$.

Ciertamente, no se puede permitir una confesionalidad encubierta; una cosa es cooperar y otra es convertir la palabra cooperación en una política de confesionalidad.

A nuestro juicio, este nivel de cooperación no debe circunscribirse a la Iglesia Católica, pues por ejemplo en España existen acuerdos celebrados con las iglesias protestante, musulmana y judía. En el Perú, no existe mayor desarrollo sobre el particular. Un paso inicial se ha dado con la Resolución

26 El TC sostuvo que «[...] la Ordenanza cuestionada tiene como finalidad contribuir a que las celebraciones de la Semana Santa - que involucra a cientos de miles de fieles, y en donde se conjuga la costumbre religiosa y el fervor popular- se lleven a cabo en armonía con el deseado orden material. De allí que la prohibición de consumo de alcohol en esa particular circunstancia obtenga justificación jurídica» (F.J. 30). y Constitucionales, 2006, p. 183. 
Ministerial $N^{\circ}$ 377-2003-JUS, publicada el 15 de octubre de 2003, que crea una Registro de Confesiones distintas a la Católica.

\section{La necesidad de un desarrollo legal de la libertad religiosa}

El 27 de febrero de 2007 la célula parlamentaria aprista presentó el Proyecto de Ley 1008-2006-CR, que permitiría que el país cuente con su primera Ley de Libertad e Igualdad Religiosas ${ }^{28}$. Conforme señala su Exposición de Motivos, aquel hacía suya la propuesta formulada por la Mesa de Trabajo constituida mediante Resolución Ministerial Nº 070-2005-JUS. El texto cuenta con veintisiete artículos, una disposición transitoria y dos disposiciones finales. Esta propuesta va de la mano con lo señalado en el Plan Nacional de Derechos Humanos 2006-2010 que consideró como una de las actividades necesarias para fortalecer el marco de protección jurídica de la libertad de conciencia y religión "promover que se precisen los alcances del artículo 2, numeral 3 de la Constitución $[\ldots] \aleph^{29}$.

En otros países existen leyes similares, tal como sucede en España que cuenta con la Ley Orgánica 7/1980, de 5 de julio, de Libertad Religiosa; en Colombia donde existe la Ley 133 del 23 de mayo de 1994, y en Chile que cuenta con la Ley 19.638 del 22 de septiembre de 1999.

\section{DisPosiciones GENERALES}

El proyecto de ley en sus trece primeros artículos - Disposiciones Generales- desarrolla los alcances de la libertad e igualdad religiosas, el principio de neutralidad y la cooperación de las iglesias con el Estado.

$\mathrm{Al}$ referirse a la protección del ejercicio de creencias religiosas (artículo 3) el proyecto desarrolla diversos aspectos. En uno de ellos se señala que «los documentos oficiales de identificación no contendrán mención sobre las creencias o no creencias religiosas de una persona». Aunque esta prohibición surge de lo dispuesto por el artículo 2 inciso 18) de la Constitución

28 El referido proyecto hasta el cierre de la legislatura ordinaria, en junio de 2008, no contaba con dictamen de la Comisión de Constitución y Reglamento.

29 El referido Plan fue aprobado mediante Decreto Supremo 017-2007-JUS11 de diciembre de 2005, p. 305969. 
que reconoce el derecho de mantener reserva sobre las convicciones religiosas, las entidades públicas no siempre lo respetan. Por ejemplo, en el último censo nacional realizado el 21 de octubre de 2007 el Instituto Nacional de Estadística e Informática (INEI) incluyó en la cédula censal la siguiente pregunta «¿cuál es su religión?». De acuerdo a las normas del censo, las personas debían obligatoriamente responder bajo amenaza de multa, lo cual resultaba manifiestamente inconstitucional. Por ello, creemos que el proyecto no solo debería circunscribirse a los documentos oficiales de identificación sino a «todos» los documentos oficiales.

Como bien reconoce la doctrina un «complemento intrínseco de la libertad religiosa es la igualdad en materia religiosa ${ }^{30}$. Por ello, hace bien el proyecto al reconocer en plano de igualdad a las distintas confesiones (artículo 10), a fin de evitar situaciones de discriminación que en otros países han motivado pronunciamientos jurisdiccionales. Como ya lo hemos señalado, la Corte Constitucional de Colombia, a través de la Sentencia $\mathrm{N}^{\circ} \mathrm{C}-027 / 93$ de 5 de febrero de 1993, declaró inconstitucionales algunos artículos del Concordato y Protocolo Final entre la República de Colombia y la Santa Sede, suscrito en Bogotá el 12 de julio de 1973 y aprobado por la Ley 20 de 1974. Uno de los temas declarados inconstitucionales fue el referido a la educación religiosa católica en los centros educativos públicos pues consideró que se trataba de un supuesto discriminatorio. Ello explica que el artículo 3 de la Ley de Libertad Religiosa de Colombia precise que «Todas las confesiones religiosas e Iglesias son igualmente libres ante la Ley».

Sin embargo, resulta necesario efectuar algunas precisiones a una parte de dicho articulado. En efecto, al referirse a la objeción de conciencia como supuesto que permite abstenerse de cumplir un deber (artículo 4, a), sería conveniente indicar que los casos de objeción de conciencia son aquellos que «expresamente señale la ley». Ello pues la objeción de conciencia no es un derecho absoluto, por ejemplo, no debe proceder en materia tributaria. Además, sería conveniente agregar que: «En ningún caso, el ejercicio de la objeción de conciencia podrá evitar la falta de atención de un servicio público a la ciudadanía. El Estado deberá adoptar las medidas necesarias para garantizar dicha atención». Se pretende con ello evitar que

30 Barrero Ortega, Abraham. Ob. cit., p. 137. 
por razones religiosas se deje sin atención a las personas. Este caso se podría presentar, por ejemplo, si todos los médicos ginecólogos de un hospital público se negaran por razones religiosas a brindar métodos anticonceptivos a sus pacientes. El Estado debería garantizar que ello no ocurra y brindar el servicio a través de médicos que no sean objetores de conciencia.

Asimismo, cuando se regulan las posibles limitaciones a la libertad religiosa el proyecto menciona que están referidas al «ejercicio del derecho ajeno, las normas de orden público y las buenas costumbres» (artículo 4, primer párrafo). Nos parece más apropiado seguir el texto del artículo 2 inciso 3) de la Constitución, según el cual el ejercicio de este derecho no debe ofender la moral ni el orden público. Así también lo ha entendido el Tribunal Constitucional (Exp. No 0256-2003-HC/TC, F.J.17) al precisar que:

[...] como sucede con cualquier derecho fundamental, tampoco el ejercicio de la libertad religiosa, en cuyo ámbito se encuentra comprendido el de la libertad de culto, es absoluto. Está sujeto a límites. Uno de ellos es el respeto al derecho de los demás. Este límite forma parte del contenido del derecho en su dimensión negativa, que, como se ha recordado, prohíbe la injerencia de terceros en la propia formación de las creencias y en sus manifestaciones. También constituye un límite la necesidad de que su ejercicio se realice en armonía con el orden público; particularmente, con la libertad de culto. Asimismo, se encuentra limitado por la moral y la salud públicas. Tales restricciones deben ser evaluadas en relación con el caso concreto e interpretadas estricta y restrictivamente.

Del mismo modo, nos parece importante reconocer expresamente el «principio de neutralidad» de tal modo que se evidencie la autonomía que existe entre el Estado y las confesiones religiosas. Al respecto, por ejemplo, la ley española es muy explícita al señalar que «Ninguna confesión tendrá carácter estatal» (artículo 1.3).

En todo caso, consideramos que requiere un mayor debate y revisión lo dispuesto por el artículo 7 del Proyecto según el cual «las Entidades Religiosas son personas jurídicas de derecho público». En efecto, si bien tal personería jurídica se puede justificar tratándose de la Iglesia Católica pues ella representa al Estado Vaticano y es un sujeto del Derecho Internacional, es difícil considerar que otras entidades religiosas puedan contar con personería jurídica de derecho público, pues en estricto no ejercen funciones públicas o administrativas y tampoco representan a ningún Estado. Así por 
ejemplo, el artículo 5 de la Ley española señala que «Las Iglesias, Confesiones y Comunidades religiosas y sus Federaciones gozarán de personalidad jurídica una vez inscritas en el correspondiente Registro Público, que se crea, a tal efecto, en el Ministerio de Justicia». En la actualidad, como se sabe, las confesiones religiosas distintas a la Católica están constituidas como asociaciones privadas.

\section{LiBERTAD E IGUALDAD RELIGIOSAS}

El artículo 14 del proyecto regula los alcances de la libertad de conciencia y religión, precisando varias facultades, muchas de las cuales han sido desarrolladas por la jurisprudencia del Tribunal Constitucional.

Un primer aspecto, sería distinguir los alcances de ambos derechos. En efecto, el Tribunal Constitucional ha mencionado que «en puridad, la libertad de conciencia está vinculada a la libertad de ideas; mientras que la libertad de religión, a la libertad de creencias» (Caso Lucio Valentín Rosado Adanaque, Exp. N 0895-2001-AA/TC-Lambayeque, resuelto el 19 de agosto de 2002, FJ. 3). Si aceptamos tal distinción, lo dispuesto por el artículo 14 del proyecto estaría referido fundamentalmente a los alcances de la libertad religiosa y no tanto a la libertad de conciencia ${ }^{31}$.

De otro lado, lo señalado por el inciso l) del citado dispositivo del proyecto motivó una sentencia del TC donde se entendió que Essalud no podía obligar a un médico adventista a trabajar los días sábados porque ello afectaba sus convicciones religiosas. En tal ocasión, el Tribunal declaró fundada la demanda y ordenó «a la demandada no incluir al recurrente en las jornadas laborales de los días sábados y permitirle tomar todas las medidas razonables que la ley autorice para compensar dichas inasistencias, de forma tal que no se vea afectada la productividad laboral del recurrente» (Expediente $\mathrm{N}^{\circ}$ 0895-2001-AA/TC-Lambayeque). Es decir, ya existe un criterio jurisprudencial que avala un dispositivo de tal naturaleza.

31 Mosquera Monelos, Susana. «El derecho de libertad de conciencia y de religión en el ordenamiento jurídico peruano». Universidad de Piura, 2005, p. 147. 


\section{LA IMPORTANCIA DE CONTAR CON UN REgistro DE ENTIDADES RELIGIOSAS}

Es importante que el proyecto regule un registro voluntario de instituciones religiosas, así como de sus autoridades o representantes, pues brinda garantías de publicidad suficientes a este tipo de actos. Dicha propuesta tiene como antecedente la Resolución Ministerial No 377-2003-JUS, publicada el 15 de octubre de 2003, que creó un Registro de Confesiones distintas a la Católica. La citada resolución estableció los requisitos para inscribirse, las entidades y actividades comprendidas, la existencia de una Comisión Asesora en Asuntos Confesionales en el Ministerio de Justicia, entre otros aspectos.

El reconocimiento a través de un registro resulta de especial relevancia para las instituciones no católicas, pues la Iglesia Católica cuenta, como hemos mencionado, con un Acuerdo que data de julio de 1980. Además, sería importante que el proyecto mencione en forma expresa que se trata de un registro «de carácter público».

\section{El PATRIMONIO Y LAS EXENCIONES}

La forma de financiamiento de las entidades religiosas y la posibilidad que el Estado establezca formas de colaboración con ellas, es el marco que permitiría otorgarles un financiamiento público directo o que el mismo se obtenga a través de exoneraciones e inafectaciones tributarias. El proyecto opta por este segundo modelo, lo cual nos parece lo más apropiado, y trata de garantizar el principio de igualdad de las restantes confesiones con la Iglesia Católica, pues como hemos visto en virtud del Acuerdo de julio de 1980 ella cuenta con indudables ventajas tributarias.

En efecto, la Iglesia Católica en virtud de dicho Acuerdo y de la interpretación del mismo goza de un "régimen de exoneración permanente». Así lo consideró el Ministerio de Relaciones Exteriores en el Oficio OF. RE (LEG) No 2-5-E/900, de 9 de octubre de 2003, dirigido a la entonces Superintendente Nacional de Administración Tributaria, señora Nahil Hirsch Carrillo. En dicha comunicación se afirmaba respecto al Acuerdo con la Santa Sede que: «Si bien el universo tributario entonces vigente no alcanzaba tributos no existentes en ese momento, resulta evidente que la 
voluntad de las partes fue crear un régimen de exoneración permanente». A partir de ello, el Ministerio de Relaciones Exteriores concluía que:

1. Las Misiones de la Iglesia Católica pueden invocar la protección tributaria contenida en Acuerdo suscrito entre el Gobierno del Perú y la Santa Sede, es decir, las inafectaciones en sus asuntos propios, las exoneraciones y beneficios tributarios, así como las franquicias reconocidas en dicho Acuerdo.

2. Las inafectaciones tributarias alcanzan a todas las actividades propias de la Iglesia, las mismas que están establecidas en el derecho canónico en general. [...].

3. [...] Siendo el Vaticano un Estado, todos los asuntos relacionados con sus representantes deben ser gestionados y coordinados con la Nunciatura Apostólica, como representantes de El Vaticano, y a través de esta Cancillería.

Cabe indicar que dicho oficio se remitió con motivo de la denuncia presentada contra una institución de la Iglesia Católica, titular de un camposanto, ante INDECOPI por competencia desleal. La denuncia se amparaba en el Informe $\mathrm{N}^{\circ}$ 001-2003-SUNAT/2B3000, de fecha 07 de enero de 2003 que concluía señalando que «La cesión en uso - temporal o perpetua- de sepulturas a título oneroso que realice una Misión integrante de la Iglesia Católica, propietaria de un cementerio, se encuentra gravada con el IGV y el IPM.». El Tribunal de Defensa de la Competencia y de la Propiedad Intelectual, Sala de Defensa de la Competencia, declaró infundada la denuncia presentada pues consideró que:

De acuerdo con lo informado por el Ministerio de Relaciones Exteriores, la voluntad de las partes que suscribieron el Acuerdo Internacional celebrado entre el Estado Peruano y la Santa Sede el 19 de julio de 1980, fue la de crear un régimen de exoneración permanente a favor de la Iglesia Católica, y que las inafectaciones tributarias que este establece alcanzan a todas las actividades propias de la Iglesia, incluyendo la actividad realizada por los cementerios. En este sentido, la Misión Cementerio Católica Parque del Recuerdo no ha incurrido en actos de competencia desleal [...]

En el Perú se han presentado casos en los cuales Iglesias y colegios religiosos no católicos han exigido un tratamiento tributario igual al que gozan sus similares católicos. El proyecto trata de corregir esta desigualdad de 
trato. Incluso algunos casos han llegado a los tribunales. Así por ejemplo, el 27 de abril de 1998 la Misión del Sínodo Evangélico Luterano en el Perú interpuso demanda de amparo contra la Municipalidad Metropolitana de Lima. Dicha institución consideraba que estaba siendo discriminada pues la inafectación al pago de tributos solo beneficiaba a la Iglesia Católica, excluyendo a las demás organizaciones religiosas (Expediente $\mathrm{N}^{\circ} 1123$ 99-AA/TC). El 15 de junio de 2000, el Tribunal Constitucional declaró improcedente la demanda.

\section{LA POSIBILIDAD DE SUSCRIBIR CONVENIOS DE COLABORACIÓN}

La Constitución reconoce el deber de cooperación, el mismo que no debe circunscribirse a la Iglesia Católica. Así por ejemplo en otros países, como España, la Ley Orgánica 7/1980 de Libertad Religiosa autoriza la existencia de acuerdos o convenios de cooperación (artículo 7). Ello ha permitido que «la Federación de Entidades Religiosas Evangélicas de España (FEREDE), la Federación de Comunidades Israelitas (FCI) y la Comisión Islámica de España (CIE) hayan firmado Acuerdos con el Estado español ${ }^{32}$.

Estas «formas de cooperación» con otras confesiones podrán otorgarles «las mismas ayudas a las demás religiones», no deberán atentar «contra las creencias de otras personas o a quienes no tienen creencias religiosas» $y$ establecer beneficios en función de la «relevancia religiosa» de las actividades $^{33}$, entre otros aspectos. En el Perú, no ha existido mayor desarrollo sobre el particular. Por ello, es importante que el proyecto de ley autorice este tipo de convenios que el Estado puede celebrar con las distintas confesiones religiosas en un plano de igualdad. Sin embargo, sería importante que el texto precise a través de que instrumento jurídico se formaliza la aprobación de estos acuerdos. A nuestro juicio debería ser un «acto administrativo» del respectivo nivel de gobierno.

\footnotetext{
Barrero Ortega, Abraham. Ob. cit., p. 361.

Carpio Marcos, Edgar y Juan Manuel Sosa Sacio. «Artículo 50. Iglesia Católica». En Walter GutiérREZ (Director). «La Constitución comentada. Análisis artículo por artículo», Tomo I. Lima: Gaceta Jurídica - Congreso de la República, 2005, p. 732.
} 


\section{Reflexiones finales}

Las relaciones entre el Estado y la Iglesia a lo largo del constitucionalismo peruano (siglos XIX y parte del XX) se han caracterizado por considerar a la religión católica como la oficial, excluyendo a todas las demás. Esta situación cambió con motivo de la aprobación de la Constitución de 1979, vigente en julio de 1980, la cual aunque mantuvo una mención especial a la Iglesia Católica, reconoció la autonomía e independencia entre el Estado y la Iglesia, la libertad religiosa, y la colaboración del Estado con otras confesiones.

El 19 de julio de 1980 se suscribió un Acuerdo entre el Estado peruano y la Santa Sede que elevó a manera de tratado entre dos Estados determinados privilegios que ya venía gozando la Iglesia Católica y que no beneficiaban ni benefician a las restantes confesiones religiosas. En otros países, como Colombia, el Tribunal o Corte Constitucional ha cuestionado algunos de estos acuerdos porque han generado supuestos de discriminación frente a otras confesiones.

La Constitución de 1993 se inspiró en lo dispuesto por la Constitución anterior y mantiene la autonomía e independencia entre el Estado y la Iglesia. Dicho texto coexiste con el Acuerdo suscrito con la Iglesia Católica. La libertad e igualdad religiosas, el principio de neutralidad y el reconocimiento de la colaboración del Estado con todas las confesiones religiosas sin discriminación alguna, son aspectos fundamentales para la consolidación de un Estado Constitucional de Derecho. Para contribuir a superar ello es importante contar con una ley que desarrolle estos principios y que garantice la libertad e igualdad religiosas, tal como existe en otros países.

Se ha presentado al Congreso de la República un proyecto de ley que recoge la propuesta formulada por la Mesa de Trabajo constituida mediante Resolución Ministerial No 070-2005-JUS, y que tiene alcances sumamente positivos. A nuestro juicio, solo sería necesario efectuar algunas precisiones que hemos mencionado a lo largo del presente artículo. Con independencia de ello, sería importante que el Congreso de la República debata y apruebe un proyecto de ley de esta naturaleza. 
En definitiva, la libertad religiosa y el principio de neutralidad son aspectos fundamentales para la consolidación de un Estado Constitucional de Derecho. Sin embargo, en la realidad subsiste una fuerte presencia de la iglesia en la vida política del país. Para superar ello, no es suficiente una declaración constitucional que proclame un Estado laico y que excluya toda mención a determinada religión, sino que resulta indispensable que la ciudadanía interiorice el rol que le corresponde a la Iglesia y el rol que le compete al Estado. En otros países, los Tribunales Constitucionales han contribuido a fortalecer la neutralidad, tal como por ejemplo ha sucedido en Colombia; en el Perú, todavía se requiere un mayor desarrollo jurisprudencial sobre estos temas. 